\title{
DFT Exploration on Molecular Characteristics of tetrahydropyrimidine-5-carboxylate
}

\author{
Abhijit R. Bukane*, Bapu S. Jagdale \\ PG Department of Chemistry, Mahatma Gandhi Vidyamandir's Arts, Science and Commerce College (Affiliated to S.P.P.U., Pune), Manmad, \\ Nashik - 423 104, Maharashtra, India.
}

\section{A R T IC LE DET A I L S}

Article history:

Received 27 March 2021

Accepted 07 April 2021

Available online 09 April 2021

\section{Keywords:}

B3LYP/6-311G(d,p)

Dihydropyrimidinone DFT

\begin{abstract}
A B S T RAC T
Present investigation deals with the synthesis and density functional theory study (DFT) of a Biginelli adduct; 6-methyl-2-oxo-4-phenyl-1,2,3,4-tetrahydropyrimidine-5-carboxylate (MOPTHPC). The synthesis of a MOPTHPC has been carried out by the reaction of benzaldehyde, ethyl acetoacetate and urea in ethanol $70-80^{\circ} \mathrm{C}$ under stirring condition in presence of catalytic amount of sulfamic acid. The structure of a synthesized chalcone is affirmed on the basis of ${ }^{1} \mathrm{H}$ NMR and ${ }^{13} \mathrm{C}$ NMR. The geometry of a MOPTHPC is optimized by using the density functional theory method at the B3LYP/6-311G(d,p) basis set. The optimized geometrical parameters like bond length and bond angles have been computed. Quantum chemical parameters have been determined and examined. Molecular electrostatic surface potential (MESP) surface plot analysis has been carried out at the same level of theory. Mulliken atomic charge study is also discussed in the present study.
\end{abstract}

\section{Introduction}

The Biginelli reaction is a multi-component reaction of aldehyde, urea, and acetoacetate, involving Mannich reaction in the first step, which furnishes multifunctionalized 3,4-dihydropyrimidin-2-(1H)-ones (DHPMs) and related heterocyclic compounds. The Biginelli reaction is frequently used for the direct synthesis of 3,4-dihydropyrimidin-2 $(1 H)$ one (DHPM) derivatives which display interesting biological activities $[1,2]$. Notable examples are calcium channel modulators [3], antibacterials [4], antivirals [5], antifungal [6] and other biological activities have been discovered in DHPMs [7-14]. Calculations in theoretical chemistry are based on physicochemical calculations and quantum chemistry. Different molecular properties can be predicted using density functional theory (DFT) [15-20]. UV/Vis spectra [21, 22], IR and Raman frequencies and intensities [23, 24], NMR chemical shifts [25], and spin-spin coupling constants [26] are the spectroscopic investigations that can be carried out. HOMO-LUMO energies [27-31], bond lengths and bond angles [32], and absorption energies [33-35] can all be predicted using DFT calculations. DFT method with B3LYP functional has gained a lot of interest in the last two decades. B3LYP stands for "Becke, 3-parameter, Lee-Yang-Parr". The structural and chemical properties of organic molecules have been effectively explored using the density functional theory based on theoretical quantum calculations [38-42]. As theoretical calculations are compared to experimental findings, a lot of knowledge is gained. It is now possible to arrive at a reaction mechanistic pathway using computation data. The current study looked at DFT analysis of molecular structure, bond length, bond angle, and Mulliken atomic charges. The DFT approach is also used to investigate important parameters such as total energy, HOMO-LUMO energies, and charge distribution. In last decades several green chemistry methods have been employed for the synthesis of variety of organic compounds [43-46]. In light of the above, I'd like to present a density functional theory investigation of previously synthesised 6methyl-2-oxo-4-phenyl-1,2,3,4-tetrahydropyrimidine-5-carboxylate (MOPTHPC) compounds in this paper.

\section{Experimental Methods}

\subsection{General Remarks}

The chemicals with high purity were purchased from Virion Enterprises, India. The chemicals were used as received without any further purification. The melting point was determined in open capillary and uncorrected. ${ }^{1} \mathrm{H}$ NMR and ${ }^{13} \mathrm{C}$ NMR spectra were recorded on a sophisticated multinuclear FT-NMR spectrometer model Advance-II (Bruker) with ${ }^{1} \mathrm{H}$ frequency $500 \mathrm{MHz}$ and ${ }^{13} \mathrm{C}$ frequency $125 \mathrm{MHz}$ using DMSO-d6 as a solvent. The reaction was monitored by thin-layer chromatography using aluminium sheets with silica gel 60 F254 (Merck).

2.2 Procedure for the Synthesis of Ethyl 6-Methyl-2-oxo-4-phenyl-1,2,3,4tetrahydropyrimidine-5-carboxylate (MOPTHPC)

As shown in Scheme 1, a mixture of benzaldehyde $(0.01 \mathrm{~mol})$, urea $(0.01$ mol), and ethyl acetoacetate, $(0.01 \mathrm{~mol})$ were mixed in $10 \mathrm{~mL}$ ethanol in the conical flask and catalytic amount of sulfamic acid were added to it. The resulting mixture was stirred on a magnetic stirrer at $70-80{ }^{\circ} \mathrm{C}$ for the required time which was monitored by TLC. The crude product was transferred into a beaker containing crushed ice, stirred, filtered, dried naturally, and recrystallized from ethanol to furnished pure white solid (m.p. $196^{\circ} \mathrm{C}-198^{\circ} \mathrm{C}$ ).
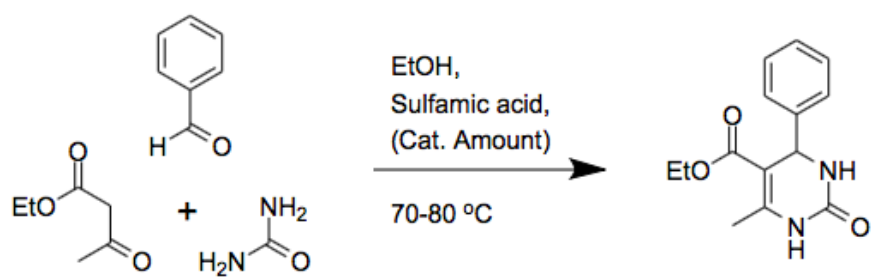

Scheme 1 Synthesis of MOPTHPC

\subsection{Computational Details}

All of the calculations for this work have been performed at DFT (B3LYP) methods with 6-311G(d,p) basis sets using the Gaussian $03 \mathrm{~W}$ program [47]. The geometry optimization of the title compound and corresponding energy were calculated with a 6-311G(d,p) basis set by assuming C1 point group symmetry. Accordingly, the optimized geometrical parameters, energy, atomic charges, dipole moment, and other thermodynamic parameters were calculated theoretically. 
Moreover, the electronic properties, such as HOMO-LUMO energies were determined using time-dependent DFT (TD-DFT) and 6-311G(d,p) basis set, in view of the optimized structure.

\section{Results and Discussion}

\subsection{Spectral Analysis}

The detailed spectral results are tabulated in Table 1 . The ${ }^{1} \mathrm{H}$ NMR spectrum predicts types and the total number of hydrogen atoms in the molecule. There are total of nine types of protons in the title molecule has furnished seven signals in the ${ }^{1} \mathrm{H}$ NMR spectrum. The two $\mathrm{NH}$ group signals are $9.18(\mathrm{~s}, 1 \mathrm{H})$ and $7.73(\mathrm{~s}, 1 \mathrm{H})$. All other signals are correctly matched with the structure of the MOPTHPC molecule. The ${ }^{13} \mathrm{C}$ NMR spectrum predicts types of carbons atoms in the molecule and therefore one can anticipate the skeleton of the molecule. There are total of twelve types of carbons that have displayed twelve signals in the ${ }^{13} \mathrm{C}$ NMR spectrum affirming the structure. The two signals 165.81 and $152.60 \delta$ are due to carbonyl carbons of ester and amide groups respectively.

Table 1 Physicochemical and spectral dada of title compound

\begin{tabular}{|c|c|}
\hline Properties & Characteristics \\
\hline Systematic Name of the Product & $\begin{array}{l}\text { 6-methyl-2-oxo-4-phenyl-1,2,3,4- } \\
\text { tetrahydropyrimidine-5-carboxylate }\end{array}$ \\
\hline Physicochemical data & $\begin{array}{l}\text { Yield: } 78 \% \text {, Colour: white solid, m.p. : } 196^{\circ} \mathrm{C} \text { - } \\
198^{\circ} \mathrm{C}\end{array}$ \\
\hline${ }^{1} \mathrm{H}$ NMR (400 MHz, DMSO-d6, $\delta$ ) & $\begin{array}{l}1.09(\mathrm{t}, J=7.0 \mathrm{~Hz}, 3 \mathrm{H}), 2.25(\mathrm{~s}, 3 \mathrm{H}), 3.98(\mathrm{q}, J= \\
7.0 \mathrm{~Hz}, 2 \mathrm{H}), 5.14(\mathrm{~s}, 1 \mathrm{H}), 7.25-7.33(\mathrm{~m}, 5 \mathrm{H}), \\
7.73(\mathrm{~s}, 1 \mathrm{H}), 9.18(\mathrm{~s}, 1 \mathrm{H})\end{array}$ \\
\hline${ }^{13} \mathrm{C}$ NMR $(100 \mathrm{MHz}, \mathrm{DMSO}-\mathrm{d} 6, \delta)$ & $\begin{array}{l}14.54,18.24,54.43,59.65,99.73,126.71, \\
127.73,128.86,145.34,148.83,152.60, \\
165.81\end{array}$ \\
\hline
\end{tabular}

\subsection{Computational Study}

\subsubsection{Molecular Structure, Bond Lengths and Bond Angle Analysis}

The optimized molecular structure of the title molecule is depicted in Fig. 1. The optimized molecular geometry provides a good deal of information about the spatial orientation of various atoms in a molecule. From optimized molecular structures, it can be easily seen that the MOPTHPC molecule possesses C1 point group symmetry due to the overall asymmetry of the molecule. Hence, the MOPTHPC is an asymmetric top molecule. This data is a lot of helpful for the determination of various spectroscopic parameters.

The structural parameters like bond lengths and bond angles for the title molecule have been established by the DFT/B3LYP method with the 6-311G(d,p) as basis set and are presented in Table 2. The MOPTHPC molecule comprises of two six-membered rings. The DFT computation predicts the benzene ring is planar (as expected) while the other ring is non-planar. The self-consistent field (SCF) energy of the title molecule at the DFT/B3LYP method with the 6-311G(d,p) as basis set is found to be -878.57 a.u. with dipole moment 3.71 Debye. The C10-C12, C13-020, and C11-026 bonds are $1.3602 \AA, 1.2168 \AA$, and $1.2161 \AA$ long respectively. The bond angles of H30-C28-027, C2-C1-C6 and N21-C11-N23, are $108.775^{\circ}, 120.2966^{\circ}$ and $113.3341^{\circ}$ respectively. The bond angle and bond length data are in good agreement with the structure of the title molecule.

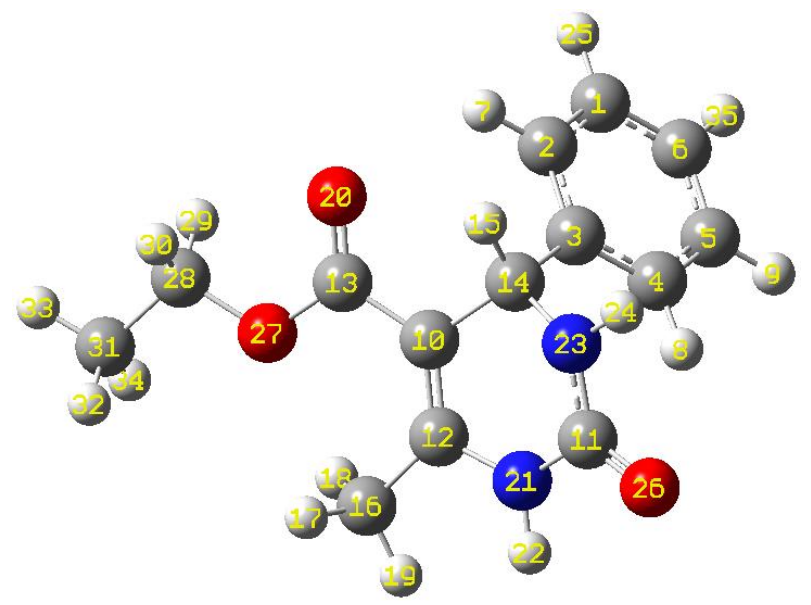

Fig. 1 Optimized molecular structure of MOPTHPC

https://doi.org/10.30799/jacs.236.21070105
Table 2 Optimized geometrical parameters of MOPTHPC by DFT/ B3LYP with 6$311 \mathrm{G}(\mathrm{d}, \mathrm{p})$ basis set

\begin{tabular}{|c|c|c|c|}
\hline \multicolumn{4}{|c|}{ Bond Lengths $(\AA)$} \\
\hline$\overline{\mathrm{C} 1-\mathrm{C} 2}$ & 1.3923 & C12-C16 & 1.5061 \\
\hline C1-C6 & 1.3934 & C12-N21 & 1.3834 \\
\hline C1-H25 & 1.0845 & $\mathrm{C} 13-020$ & 1.2168 \\
\hline $\mathrm{C} 2-\mathrm{C} 3$ & 1.4 & $\mathrm{C} 13-027$ & 1.357 \\
\hline $\mathrm{C} 2-\mathrm{H} 7$ & 1.0832 & C14-H15 & 1.0906 \\
\hline $\mathrm{C} 3-\mathrm{C} 4$ & 1.3984 & C14-N23 & 1.4645 \\
\hline C3- C14 & 1.5356 & C16-H17 & 1.0925 \\
\hline C4- C5 & 1.3938 & C16-H18 & 1.0869 \\
\hline C4-H8 & 1.0833 & C16-H19 & 1.0924 \\
\hline C5- C6 & 1.3923 & N21-H22 & 1.0085 \\
\hline C5- H9 & 1.0845 & C20-C23 & 1.5153 \\
\hline C6-H35 & 1.0843 & N23-H24 & 1.0093 \\
\hline C10-C12 & 1.3602 & O27-C28 & 1.4478 \\
\hline C10-C13 & 1.4662 & C28-H29 & 1.0923 \\
\hline C10-C14 & 1.5275 & С28-Н30 & 1.0922 \\
\hline C10-C14 & 1.5278 & C28-C31 & 1.5153 \\
\hline C11-N21 & 1.4037 & C31-H32 & 1.0923 \\
\hline C11-N23 & 1.361 & С31-H33 & 1.0932 \\
\hline C11-026 & 1.2161 & C31-H34 & 1.0924 \\
\hline \multicolumn{4}{|c|}{ Bond Angles $\left({ }^{\circ}\right)$} \\
\hline$\overline{\mathrm{C} 2-\mathrm{C} 1-\mathrm{C} 6}$ & 120.2966 & C3-C14-H15 & 107.5108 \\
\hline $\mathrm{C} 2-\mathrm{C} 1-\mathrm{H} 25$ & 119.6264 & C3-C14-N23 & 113.1114 \\
\hline C6-C1-H25 & 120.0758 & C10-C14-H15 & 107.1084 \\
\hline C1-C2-C3 & 120.6314 & C10-C14-N23 & 108.9859 \\
\hline $\mathrm{C} 1-\mathrm{C} 2-\mathrm{H} 7$ & 120.2405 & H15-C14-N23 & 107.3219 \\
\hline C3-C2-H7 & 119.1225 & C12-C16-H17 & 110.6121 \\
\hline $\mathrm{C} 2-\mathrm{C} 3-\mathrm{C} 4$ & 118.6887 & C12-C16-H18 & 111.3418 \\
\hline C2-C3-C14 & 119.3756 & C12-C16-H19 & 110.1778 \\
\hline C4-C3-C14 & 121.9352 & H17-C16-H18 & 107.1198 \\
\hline C3-C4-C5 & 120.6158 & H17-C16-H19 & 108.3867 \\
\hline C3-C4-H8 & 120.4492 & H18-C16-H19 & 109.1039 \\
\hline C5-C4-H8 & 118.9279 & C11-N21-C12 & 124.9643 \\
\hline C4-C5-C6 & 120.308 & C11-N21-H22 & 113.2921 \\
\hline C4-C5-H9 & 119.5902 & C12-N21-H22 & 119.4968 \\
\hline C6-C5-C9 & 120.1005 & C11-N23-C14 & 123.9911 \\
\hline C1-C6-C5 & 119.4564 & C11-N23-H24 & 113.8512 \\
\hline C1-C6-H35 & 120.3039 & C14-N23-H24 & 117.977 \\
\hline C5-C6-H35 & 120.2382 & C13-027-C28 & 115.6801 \\
\hline C12-C10-C13 & 126.291 & O27-C28-H29 & 108.7957 \\
\hline C12-C10-C14 & 118.9815 & О27-С28-H30 & 108.775 \\
\hline C13-C10-C14 & 114.6848 & O27-C28-C31 & 107.642 \\
\hline $\mathrm{N} 21-\mathrm{C} 11-\mathrm{N} 23$ & 113.3341 & H29-С28-H30 & 107.561 \\
\hline N21-C11-026 & 121.0623 & H29-C28-C31 & 111.9929 \\
\hline N23-C11-026 & 125.5813 & H30- C28-C31 & 111.9969 \\
\hline C10-C12-C16 & 127.5788 & C28-C31-H32 & 111.0629 \\
\hline C10-C12-N21 & 118.5132 & С28-C31-H33 & 109.6935 \\
\hline C16-C12-N21 & 113.9033 & C28-C31-H34 & 111.1053 \\
\hline C10-C13-020 & 123.3551 & H32-С31-H33 & 108.2002 \\
\hline C10-C13-027 & 114.9177 & H32-C31-H34 & 108.5105 \\
\hline O20-C13-027 & 121.7178 & H33-C31-H34 & 108.1739 \\
\hline C3-C14-C10 & 112.4893 & - & - \\
\hline
\end{tabular}

Table 3 Mulliken atomic charges

\begin{tabular}{llll}
\hline Atom & Charge & Atom & Charge \\
\hline $1 \mathrm{C}$ & -0.093711 & $19 \mathrm{H}$ & 0.099408 \\
$2 \mathrm{C}$ & -0.062545 & $20 \mathrm{O}$ & -0.380916 \\
$3 \mathrm{C}$ & -0.045872 & $21 \mathrm{~N}$ & -0.440812 \\
$4 \mathrm{C}$ & -0.080657 & $22 \mathrm{H}$ & 0.235484 \\
$5 \mathrm{C}$ & -0.097981 & $23 \mathrm{~N}$ & -0.395826 \\
$6 \mathrm{C}$ & -0.084594 & $24 \mathrm{H}$ & 0.235751 \\
$7 \mathrm{H}$ & 0.115665 & $25 \mathrm{H}$ & 0.093706 \\
$8 \mathrm{H}$ & 0.103071 & $26 \mathrm{O}$ & -0.370488 \\
$9 \mathrm{H}$ & 0.092582 & $27 \mathrm{O}$ & -0.368006 \\
$10 \mathrm{C}$ & -0.245390 & $28 \mathrm{C}$ & -0.020205 \\
$11 \mathrm{C}$ & 0.449185 & $29 \mathrm{H}$ & 0.121176 \\
$12 \mathrm{C}$ & 0.249113 & $30 \mathrm{H}$ & 0.121997 \\
$13 \mathrm{C}$ & 0.444290 & $31 \mathrm{C}$ & -0.306426 \\
$14 \mathrm{C}$ & -0.037308 & $32 \mathrm{H}$ & 0.114208 \\
$15 \mathrm{H}$ & 0.165526 & $33 \mathrm{H}$ & 0.112009 \\
$16 \mathrm{C}$ & -0.218696 & $34 \mathrm{H}$ & 0.114550 \\
$17 \mathrm{H}$ & 0.141558 & $35 \mathrm{H}$ & 0.092406 \\
$18 \mathrm{H}$ & 0.147749 & - & - \\
\hline
\end{tabular}


3.2.2 Mulliken Atomic Charges and Molecular Electrostatic Potential Surface Analysis

The Mulliken atomic charges depend on the electron density. The charge distribution on the molecules has a crucial role in the field of quantum mechanical calculations for the molecular systems. The pictorial illustration of the Mulliken atomic charges of the MOPTHPC molecule calculated by the DFT/B3LYP method with a 6-311G (d,p) basis set and tabulated in Table 3. Mulliken atomic charges reveal that all the hydrogen atoms have a net positive charge but $\mathrm{H} 22$ and $\mathrm{H} 24$ hydrogen atoms are highly electropositive with atomic charges of 0.235484 and 0.235751 respectively. This can be ascribed to attachment with a nitrogen atom in both cases. The $\mathrm{C} 11$ atom has the highest net positive charge 0.449185 whereas C31 atom has the highest net negative charge -0.306426 amongst all carbon atoms. Out of the three oxygen atoms, 020 is having more negative charge density of -0.380916 and out of the two nitrogen atoms; N21 is more negative with -0.440812 Mulliken atomic charges.

MESP is the three-dimensional portrayal of the charge appropriations on molecules. The MESP diagram plotted by utilizing a 6-311G(d,p) basis set is represented in Fig. 2. Over the span of on-going years, the MESP has risen as a convincing manual for investigating the molecular interactions. The phenomena like solvent effects, nucleophilic and electrophilic sites, hydrogen bonding forces, etc. could be predicted by the utilization of MESP plots. The different regions of the MESP plot are represented by different colors. The red and yellow surfaces are the regions of large electron density and therefore linked with nucleophilic sites. Similarly, the blue colors indicate low electron density and associated with electrophilic sites. On the other hand, green surfaces suggest regions of zero potential. The MESP proposes, in the MOPTHPC molecule, the benzene ring is highly reactive towards electrophiles. The two carbonyl group are showing high reactivity towards nucleophile and rest of the molecular moiety doesn't show a significant reactive site for electrophilic or nucleophilic reaction.

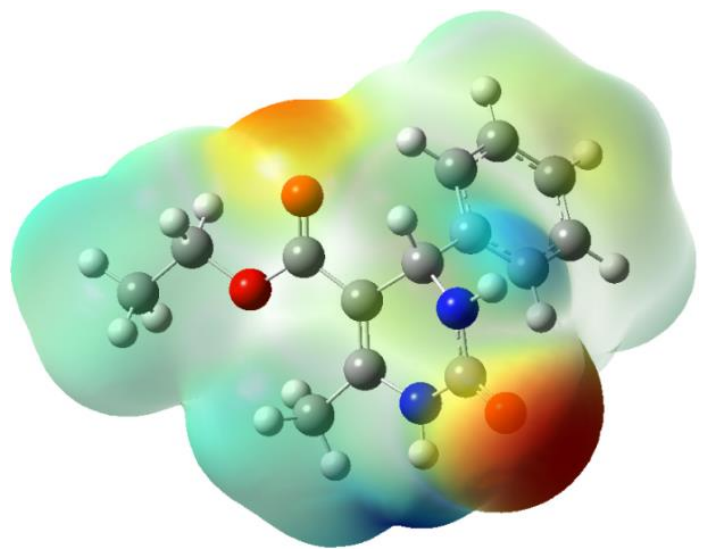

Fig. 2 MESP diagram of MOPTHPC

\subsubsection{Frontier Molecular Orbital Analysis}

The FMOs, highest occupied molecular orbital (HOMO) and lowest unoccupied molecular orbital (LUMO) are extremely crucial to anticipate the reactivity of the molecules. HOMO is the orbital which decides the nucleophilic ability whereas LUMO decides the electrophilic ability of the molecules. The energy gap between these two orbitals helps in deciding the stability. A smaller energy gap indicates high stability. Hence, one can foresee the chemical reactivity of the molecule. The expansion of the HOMO-LUMO energy gap prompts a reduction in adaptability, polarizability, and electron movement in a molecule. The HOMO energy corresponds to ionization enthalpy (I) and LUMO energy to an electron affinity (A). The pictorial outline of the FMOs has been given in Fig. 3.
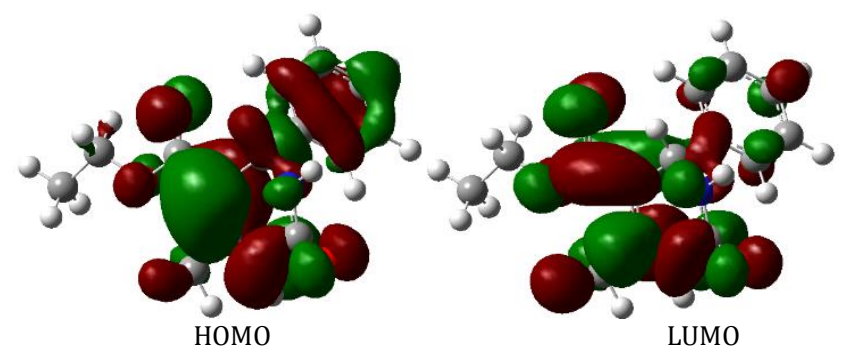

Fig. 3 HOMO-LUMO pictures of MOPTHPC

The examination of the FMOs affirms that the electron excitation corresponds to the transition from the ground state to the first excited state and is chiefly portrayed by one-electron transfer from HOMO to https://doi.org/10.30799/jacs.236.21070105
LUMO. The HOMO-LUMO energy gap suggests the inevitable charge transfer phenomenon is taking place within the MOPTHPC molecule.

The various electronic parameters of the MOPTHPC molecule are tabulated in Table 4 and reactivity descriptors in Table 5. Based on HOMO and LUMO energies and by using Koopmans' theorem various global reactivity descriptors like electronegativity $(\chi)$ absolute hardness $(\eta)$ global softness $(\sigma)$ global electrophilicity $(\omega)$ chemical potential $(\mathrm{Pi})$, the maximum number of electron transferred $(\Delta \mathrm{Nmax})$ are calculated. The electrophilicity $\omega$ scale allowed the gathering of organic molecules as strong electrophiles with $\omega>1.5 \mathrm{eV}$, moderate electrophiles with $0.8<\omega$ $<1.5 \mathrm{eV}$ and very weaker electrophiles with $\omega<0.8 \mathrm{eV}$. The title molecule MOPTHPC is a good electrophile $(\omega=2.87 \mathrm{eV})$. The $\Delta$ Nmax value of MOPTHPC molecule is $1.59 \mathrm{eV}$ indicating charge transfer. The energy gap is $5.07 \mathrm{eV}$ which indicates an inevitable electron movement within the title molecule.

Table 4 Electronic parameters of MOPTHPC

\begin{tabular}{llllll}
\hline $\begin{array}{l}\text { Total }_{\text {Tol }} \\
\text { (a.u.) }\end{array}$ & $\begin{array}{l}\text { Eномо } \\
(\mathrm{eV})\end{array}$ & $\begin{array}{l}\text { ELumo }_{\text {Lum }} \\
(\mathrm{eV})\end{array}$ & $\begin{array}{l}\Delta \mathrm{E} \\
(\mathrm{eV})\end{array}$ & $\begin{array}{l}\mathrm{I} \\
(\mathrm{eV})\end{array}$ & $\begin{array}{l}\mathrm{A} \\
(\mathrm{eV})\end{array}$ \\
\hline-878.57 & -6.35 & -1.28 & 5.07 & 6.35 & 1.28 \\
\hline
\end{tabular}

Note: Abbreviations: I, ionization potential; A, electron affinity; Note: $I=-E_{\text {номо }}$ and $A=-E_{\text {LUMO }}$

Table 5 Global reactivity parameters of MOPTHPC

\begin{tabular}{lllllll}
\hline $\begin{array}{l}\eta \\
(\mathrm{eV})\end{array}$ & $\begin{array}{l}\eta \\
(\mathrm{eV})\end{array}$ & $\begin{array}{l}\sigma \\
\left(\mathrm{eV}^{-1}\right)\end{array}$ & $\begin{array}{l}\omega \\
(\mathrm{eV})\end{array}$ & $\begin{array}{l}\mathrm{Pi} \\
(\mathrm{eV})\end{array}$ & $\begin{array}{l}\Delta \text { Nmax } \\
(\mathrm{eV})\end{array}$ & $\begin{array}{l}\text { Dipole } \\
\text { moment } \\
\text { (Debye) }\end{array}$ \\
\hline 3.82 & 2.54 & 0.39 & 2.87 & -3.82 & 1.59 & 3.71 \\
\hline
\end{tabular}

Note: $\chi=(I+A) / 2 ; \eta=(I-A) / 2 ; \sigma=1 / \eta ; \omega=P^{2} / 2 \eta ; P i=-\chi ; \Delta N \max =-P i / \eta$. Abbreviations: $\chi$, electronegativity; $\eta$ absolute hardness; $\sigma$, global softness; $\omega$, global electrophilicity; Pi, chemical potential; $\Delta N m a x$, maximum no. of electron transferred.

\section{Conclusion}

In conclusion, the MOPTHPC molecule is synthesized by a threecomponent Biginelli reaction. The structure of the MOPTHPC molecule is confirmed on the basis of ${ }^{1} \mathrm{H}$ NMR and ${ }^{13} \mathrm{C}$ NMR spectroscopic analysis. The geometry of the molecules was optimized by using a 6-311G(d,p) basis set and the geometrical parameters like bond lengths and bond angles have been computed at the same level of theory. The MOPTHPC molecule is an asymmetric top molecule with $\mathrm{C} 1$ point group symmetry. The dipole moment is 3.71 Debye. The FMO study is discussed and various chemical, electronic, and quantum chemical parameters are studied to analyze the chemical reactivity of the title molecule. The HOMO-LUMO energy gap suggests that the charge transfer phenomenon is taking place within the molecule. The MESP suggest the benzene ring is highly reactive towards electrophiles. The two carbonyl group are showing high reactivity towards nucleophile.

\section{Acknowledgment}

Author acknowledge central instrumentation facility (CIF), Savitribai Phule Pune University, Pune for NMR. Author also would like to thank Arts, Science and Commerce College, Manmad for permission and providing necessary research facilities and research assistance. Author would like to express his sincere and humble gratitude to Prof. (Dr.) A.B. Sawant for his guidance.

\section{References}

[1] Â. de Fátima, T.C. Braga, L.D.S. Neto, B.S. Terra, B.G. Oliveira, et al., A minireview on Biginelli adducts with notable pharmacological properties, J. Adv Res. 6(3) (2015) 363-373.

[2] V.A. Adole, Synthetic approaches for the synthesis of dihydropyrimidinones/thiones (biginelli adducts): a concise review, World J. Pharm. Res. 9(6) (2020) 1067-1091.

[3] K. Singh, D. Arora, K. Singh, S. Singh, Genesis of dihydropyrimidinonep calcium channel blockers: recent progress in structure-activity relationships and other effects, Mini-Rev Med. Chem. 9(1) (2009) 95-106.

[4] P. Attri, R. Bhatia, J. Gaur, B. Arora, A. Gupta, N. Kumar, E.H. Choi, Triethylammonium acetate ionic liquid assisted one-pot synthesis of dihydropyrimidinones and evaluation of their antioxidant and antibacterial activities, Arab. J. chem. 10(2) (2017) 206-214.

[5] D. Kumarasamy, B. G. Roy, J. Rocha-Pereira, J. Neyts, S. Nanjappan, et al., Synthesis and in vitro antiviral evaluation of 4-substituted 3, 4dihydropyrimidinones, Bioorg. Med Chem. Lett. 27(2) (2017) 139-142. 
[6] O.M. Singh, S.J. Singh, M.B. Devi, L.N. Devi, N.I. Singh, S.G. Lee, Synthesis and in vitro evaluation of the antifungal activities of dihydropyrimidinones, Bioorg. Med. Chem. Lett. 18(24) (2008) 6462-6467.

[7] R. Kaur, S. Chaudhary, K. Kumar, M.K. Gupta, R.K. Rawal, Recent synthetic and medicinal perspectives of dihydropyrimidinones: A review, Eur. J. Med. Chem. 132 (2017) 108-134.

[8] S. Gulati, R. Singh, R. Prakash, S. Sangwan, One-pot three component synthesis of substituted dihydropyrimidinones using fruit juices as biocatalyst and their biological studies, PloS One 15(9) (2020) 0238092:1-22.

[9] U. Divya, K. Jaspal, K. Manpreet, Antifungal activity of dihydropyrimidinones synthesized by using magnesium ferrite nanoparticles as catalyst, Agric. Res. J. 55(2) (2018) 313-317.

[10] J. Lal, S.K. Gupta, D. Thavaselvam, D.D. Agarwal, Design, synthesis, synergistic antimicrobial activity and cytotoxicity of 4-aryl substituted 3, 4dihydropyrimidinones of curcumin, Bioorg. Med. Chem. Lett. 22(8) (2012) 2872-2876.

[11] K.P. Beena, R. Suresh, A. Rajasekaran, P.K. Manna, Dihydropyrimidinones-a versatile scaffold with diverse biological activity, J. Pharm. Sci. Res. 8(8) (2016) 741-746.

[12] G.O. de Azambuja, L. Svetaz, I.L. Gonçalves, P.F. Corbelini, G.L. von Poser, et al., In vitro antifungal activity of dihydropyrimidinones/thiones against Candida albicans and Cryptococcus neoformans, Curr. Bioact. Compd. 15(6) (2019) 648655.

[13] J.P. Wan, Y. Pan, Recent advance in the pharmacology of dihydropyrimidinone, Mini-Rev Med. Chem. 12(4) (2012) 337-349.

[14] S. Chitra Antibacterial and antifungal studies 5-ethoxycarbonyl-4-Aryl6methyl-3, 4-dihydropyrimidinones, Int. Res. J. Pharmaceut. Appl. Sci. 2(6) (2012) 71-73.

[15] R. Thomas, M. Hossain, Y.S. Mary, K.S. Resmi, S. Armaković, et al., Spectroscopic analysis and molecular docking of imidazole derivatives and investigation of its reactive properties by DFT and molecular dynamics simulations, J. Mol. Struct. 1158 (2018) 156-175.

[16] V.A. Adole, R.H. Waghchaure, S.S. Pathade, M.R. Patil, T.B. Pawar, B.S. Jagdale, Solvent-free grindstone synthesis of four new (E)-7-(arylidene)-indanones and their structural, spectroscopic and quantum chemical study: a comprehensive theoretical and experimental exploration, Mol. Simul. 46 (2020) 1045-1054.

[17] M. Bouklah, H. Harek, R. Touzani, B. Hammouti, Y. Harek, DFT and quantum chemical investigation of molecular properties of substituted pyrrolidinones, Arab. J. Chem. 5(2) (2012) 163-166.

[18] V.A. Adole, T.B. Pawar, B.S. Jagdale, DFT computational insights into structural, electronic and spectroscopic parameters of 2-(2-Hydrazineyl) thiazole derivatives: a concise theoretical and experimental approach, J. Sulfur Chem. 42(2) (2021) 131-148.

[19] H.A. Ahmed, M. Hagar, O.A. Alhaddad, New chair shaped supramolecular complexes-based aryl nicotinate derivative; mesomorphic properties and DFT molecular geometry, RSC Adv. 9(29) (2019) 16366-16374.

[20] J. Frau, D. Glossman-Mitnik, A conceptual DFT study of the molecular properties of glycating carbonyl compounds, Chem. Cent. J. 11(1) (2017) 1-8.

[21] S.L. Dhonnar, V.A. Adole, N.V. Sadgir, B.S. Jagdale, Structural, spectroscopic (UVVis and IR), electronic and chemical reactivity studies of (3, 5-diphenyl-4, 5dihydro-1H-pyrazol-1-yl)(phenyl) methanone, Phys. Chem. Res. 9(2) (2021) 193-209.

[22] A. Ayeshamariam, S. Ramalingam, M. Bououdina, M. Jayachandran, Preparation and characterizations of $\mathrm{SnO}_{2}$ nanopowder and spectroscopic (FT-IR, FTRaman, UV-Visible and NMR) analysis using HF and DFT calculations, Spectrochim. Acta A Mol. Biomol. Spectrosc. 118 (2014) 11351143.

[23] M. Raja, R.R. Muhamed, S. Muthu, M. Suresh, Synthesis, spectroscopic (FT-IR, FT-Raman, NMR, UV-Visible), first order hyperpolarizability, NBO and molecular docking study of (E)-1-(4-bromobenzylidene) semicarbazide, J. Mol. Struct. 1128 (2017) 481-492.

[24] P. Manjusha, S. Muthu, B.R. Raajaraman, Density functional studies and spectroscopic analysis (FT-IR, FT-Raman, UV-visible, and NMR) with molecular docking approach on an antifibrotic drug Pirfenidone, J. Mol. Struct. 1203 (2020) 127394

[25] M. Bühl, M. Kaupp, O.L. Malkina, V.G. Malkin, The DFT route to NMR chemical shifts, J. Comput, Chem. 20(1) (1999) 91-105.

[26] V.G. Malkin, O.L. Malkina, D.R. Salahub, Calculation of spin-spin coupling constants using density functional theory, Chem. Phy. Lett. 221 (1994) 91-99.

[27] E. Barim, F. Akman, Synthesis, characterization and spectroscopic investigation of N-(2-acetylbenzofuran-3-yl) acrylamide monomer: Molecular structure, HOMO-LUMO study, TD-DFT and MEP analysis, J. Mol. Struct. 1195 (2019) 506513.

[28] S.S. Pathade, V.A. Adole, B.S. Jagdale, T.B. Pawar, Molecular structure, electronic, chemical and spectroscopic (UV-visible and IR) studies of 5-(4- chlorophenyl)-3-(3, 4-dimethoxyphenyl)-1-phenyl-4, 5-dihydro-1H-pyrazole: combined DFT and experimental exploration, Mat. Sci. Res. India 17(specialissue2020) (2020) 27-40.

[29] P. Vennila, M. Govindaraju, G. Venkatesh, C. Kamal, Molecular structure, vibrational spectral assignments (FT-IR and FT-Raman), NMR, NBO, HOMOLUMO and NLO properties of O-methoxybenzaldehyde based on DFT calculations, J. Mol. Struct. 1111 (2016) 151-156.

[30] R.A. Shinde, V.A. Adole, B.S. Jagdale, T.B. Pawar, B.S. Desale, R.S. Shinde, Efficient Synthesis, spectroscopic and quantum chemical study of 2, 3dihydrobenzofuran labelled two novel arylidene indanones: A comparative theoretical exploration, Mat. Sci. Res. India 17(2) (2020) 146-161.

[31] M.K. Priya, B.K. Revathi, V. Renuka, S. Sathya, P.S. Asirvatham, Molecular structure, spectroscopic (FT-IR, FT-Raman, ${ }^{13} \mathrm{C}$ and ${ }^{1} \mathrm{H}$ NMR) analysis, HOMOLUMO energies, Mulliken, MEP and thermal properties of new chalcone derivative by DFT calculation, Mater. Today 8 (2019) 37-46.

[32] V.A. Adole, B.S. Jagdale, T.B. Pawar, B.S. Desale, Molecular structure, frontier molecular orbitals, MESP and UV-visible spectroscopy studies of Ethyl 4-(3, 4dimethoxyphenyl)-6-methyl-2-oxo-1,2,3,4-tetrahydropyrimidine-5carboxylate: A theoretical and experimental appraisal, Mat. Sci. Res. India 17 (specialissue2020) (2020) 13-36.

[33] M.A. Iramain, A.E. Ledesma, E. Imbarack, P.L. Bongiorno, S.A. Brandán, Spectroscopic studies on the potassium 1-fluorobenzoyltrifluoroborate salt by using the FT-IR, Raman and UV-Visible spectra and DFT calculations, J. Mol. Struct. 1204 (2020) 127534.

[34] V. Arjunan, T. Rani, C.V. Mythili, S. Mohan, Synthesis, FTIR, FT-Raman, UVvisible, ab initio and DFT studies on benzohydrazide, Spectrochim. Acta A Mol. Biomol. Spectrosc. 79(3) (2011) 486-496.

[35] V.A. Adole, R.H. Waghchaure, B.S. Jagdale, T.B. Pawar, Investigation of structural and spectroscopic parameters of ethyl4-(4-isopropylphenyl)-6methyl-2-oxo-1,2,3,4-tetrahydropyrimidine-5-carboxylate: a DFT Study Chem. Bio. Interf. 10(1) (2020) 22-30

[36] T.B. Pawar, B.S. Jagdale, A.B. Sawant, V.A. Adole, DFT studies of 2-[(2 substitutedphenyl) carbamoyl] benzoic acids, J. Chem. Biol. Phys. Sci. 7 (2017) 167-175.

[37] R.A. Shinde, V.A. Adole, B.S. Jagdale, T.B. Pawar, Experimental and theoretical studies on the molecular structure, FT-IR, NMR, HOMO, LUMO, MESP, and reactivity descriptors of (E)-1-(2,3-dihydrobenzo [b][1,4] dioxin-6-yl)-3-(3, 4, 5-trimethoxyphenyl) prop-2-en-1-one, Mat. Sci. Res. India, 17(specialissue2020) (2020) 54-72.

[38] V.A. Adole, P.B. Koli, R.A. Shinde, R.S. Shinde, Computational insights on molecular structure, electronic properties, and chemical reactivity of (E)-3-(4chlorophenyl)-1-(2-hydroxyphenyl) prop-2-en-1-one, Mat. Sci. Res. India, 17(specialissue2020) (2020) 41-53.

[39] V.A. Adole, R.H. Waghchaure, B.S. Jagdale, T.B. Pawar, S.S. Pathade, Molecular tructure, frontier molecular orbital and spectroscopic examination on dihydropyrimidinones: a comparative computational approach, J. Adv. Sci. Res. 11(2) (2020) 64-70.

[40] R.H. Waghchaure, T.B. Pawar, Synthesis, characterization, molecular structure, and HOMO-LUMO study of 2-phenylquinoxaline: a DFT exploration, World J. Pharm. Res. 9(6) (2020) 1867-1881.

[41] V.A. Adole, V.R. Bagul, S.A. Ahire, R.K. Pawar, G.B. Yelmame, A.R. Bukane, Computational chemistry: molecular structure, spectroscopic (UV-visible and IR), electronic, chemical and thermochemical analysis of 3'-phenyl-1,2dihydrospiro[indeno [5,4-b], J. Adv. Sci. Res. 12(1) (2021) 276-286.

[42] V.A. Adole, B.S. Jagdale, T.B. Pawar, A.B. Sawant, Experimental and theoretical exploration on single crystal, structural, and quantum chemical parameters of (E)-7-(arylidene)-1,2,6,7-tetrahydro-8H-indeno [5,4-b] furan-8-one derivatives: A comparative study, J. Chin. Chem. Soc. 67(10) (2020) 1763-1777.

[43] V.A. Adole, T.B. Pawar, P.B. Koli, B.S. Jagdale, Exploration of catalytic performance of nano- $\mathrm{La}_{2} \mathrm{O}_{3}$ as an efficient catalyst for dihydropyrimidinone/thione synthesis and gas sensing, J. Nanostruct. Chem. 9(1) (2019) 61-76

[44] V.A. Adole, R.A. More, B.S. Jagdale, T.B. Pawar, S.S. Chobe, Efficient synthesis, antibacterial, antifungal, antioxidant and cytotoxicity study of 2-(2hydrazineyl)thiazole derivatives, Chem. Select 5(9) (2020) 2778-2786.

[45] V.A. Adole, B.S. Jagdale, T.B. Pawar, A.A. Sagane, Ultrasound promoted stereoselective synthesis of 2, 3-dihydrobenzofuran appended chalcones at ambient temperature, S. Afr. J. Chem. 73 (2020) 35-43.

[46] S.S. Chobe, V.A. Adole, K.P. Deshmukh, T.B. Pawar, B.S. Jagdale, Poly (ethylene glycol)(PEG-400): A green approach towards synthesis of novel pyrazolo [3,4d] pyrimidin-6-amines derivatives and their antimicrobial screening, Arch. Appl. Sci. Res. 6(2) (2014) 61-66.

[47] M.J. Frisch, G.W. Trucks, H.B. Schlegel, G.E. Scuseria, M.A. Robb, Gaussian 03, Revision C.02, Gaussian, Inc., Wallingford CT, 2004. 